\title{
SOME CONSIDERATIONS ON SHEAR AND TORSION IN R/C STRUCTURAL MEMBERS IN FIRE
}

\author{
Submitted to Journal of Structural Fire Engineering - January-March 2017
}

\begin{abstract}
Structural designers are seldom required to design from scratch or to check existing $\mathrm{R} / \mathrm{C}$ structures or members in fire, under pure shear or torsion, because the structural response is in most cases controlled by either bending (with/without an axial force) or by shear with some bending. Furthermore, hardly a single test has been carried out under prevailing shear or torsion in fire. How to design or to check a shear- or torsionsensitive $\mathrm{R} / \mathrm{C}$ member in fire is, therefore, an open issue, which needs a reasonable answer based on available design models and on knowledge of the shear-resistant mechanisms active in reinforced concrete. In this paper, well-known design models used in calculations at the ultimate limit state in ordinary environmental conditions are referred to and their use in fire is discussed, with reference to both solid and thinwalled open sections. Both the effective-section method and the zone method are treated, as well as the fire-sensitivity of the various shear-transfer mechanisms, active in both shear and torsion, related to bending in concrete teeth, aggregate interlock, dowel action along the cracks, and stirrups. On the whole, what emerges clearly in fire is the increasing role played by the stirrups in shear and by the relatively cold concrete core in torsion.
\end{abstract}

\section{INTRODUCTION}

Shear and torsion as such occur very rarely in $\mathrm{R} / \mathrm{C}$ structures, as in most cases other - and larger - internal forces (such as bending moments and axial forces) come into play on extended parts of the member, while shear as such may concern single sections, and torsion may be unnecessary to guarantee equilibrium at the ultimate limit state (ACI, 2008). Shear, however, tends to be the controlling force in certain localized zones (D-zones or discontinuity zones, Reineck, 2002; Reineck and Novak, 2010), while torsion tends to be a critical issue more for the overall construction than for each single member. 
In the case of torsion, neglecting its effect in ordinary design is justified by at least two further reasons: (a) traditional $\mathrm{R} / \mathrm{C}$ structures consist of parallel $2 \mathrm{D}$ frames connected by one-way slabs - or systems of joists and slabs - which transmit shear and bending to the beams of the frames, but little or negligible torsion, and (b) the static redundancy typical of most $\mathrm{R} / \mathrm{C}$ structures generally provides alternative resisting paths inducing extra shear and extra bending, which do not require torsion to ensure equilibrium (secondary or compatibility torsion, as opposed to primary torsion whenever torsional resistance is instrumental in guaranteeing equilibrium).

Another more general yet more complex reason is that essentially resistance is a sectional issue in bending, as one or more cracked sections provide resistance in accordance with a statically-determinate mechanism (a couple of forces). On the contrary, in both shear and torsion, resistance is provided by several mechanisms, which develop over portions of the structural members and are - on the whole statically redundant. Such reasons are valid also in fire conditions, as all the resisting mechanisms active at room temperature continue to be active in fire.

To return to the static redundancy commonly found in $\mathrm{R} / \mathrm{C}$ structures, shearinduced failures in fire may occur not only because of the high temperature in itself (causing the deterioration of the materials), but also because of the indirect actions induced by redundancy. A very recent case is illustrated in Figure 1 (Burnier, 2016), which refers to an underground car park in Montreux (Switzerland), where a fire erupted in the early morning of December 9, 2010, due to the burning of two cars.

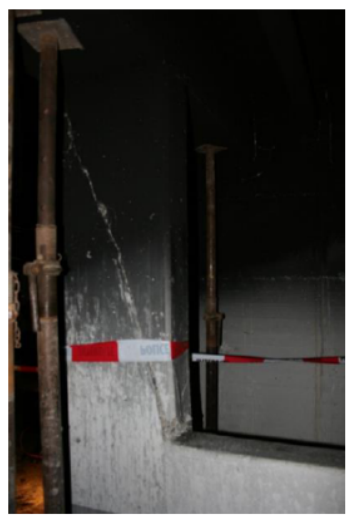

(a)

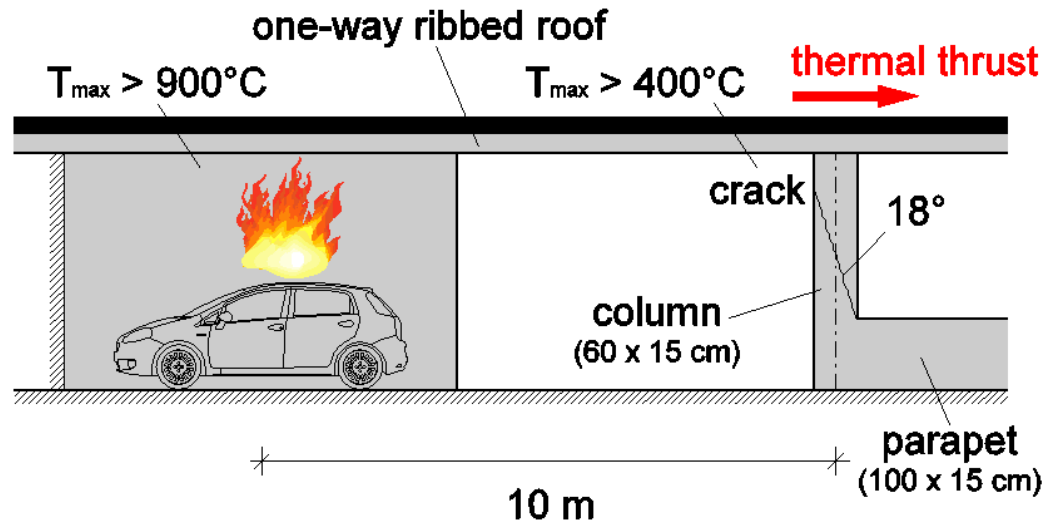

(b)

Figure 1. An example of shear-type failure in an R/C column located in an underground car park (adapted from Burnier, 2016): (a) crack pattern; and (b) structural layout.

The fire burned for one hour and developed an estimated thermal power of 5.5 MW after 35 minutes. (In similar cases, the thermal power may exceed $8 \mathrm{MW}$ ). The estimated maximum temperature in the garage exceeded $900^{\circ} \mathrm{C}$, but at a distance of $10 \mathrm{~m}$ the estimated maximum temperature was only slightly above $400^{\circ} \mathrm{C}$. In spite of this relatively low temperature, a fairly short column $10 \mathrm{~m}$ away from the two burning cars failed in shear because of the thermal thrust exerted by the ribbed roof, which was monolithically connected to the roof and to the walls of the box, and - of course - to the column. The angle of the crack was consistent with a compressive stress close to 7-8 $\mathrm{MPa}$ and with the tensile strength of 2.5-3.0 MPa typically found in ordinary concrete $\left(f_{c}=25-30 \mathrm{MPa}\right)$. This shear-type failure was caused by a fire, but not by high temperature in the collapsed member! 
Within this context, first the design models provided by the codes for shear and torsion in $\mathrm{R} / \mathrm{C}$ are discussed in this paper. They are then adjusted to fire conditions.

In shear, the validity of the reduced-or effective-section method is discussed for solid sections (where the thermal field is far from uniform), while the zone method is shown to be instrumental in analyzing thin-walled members (where the thermal field tends to be rather uniform throughout the thickness).

In torsion, the hollow-prism or tube analogy still provides a reasonable and viable model, though it neglects the contribution of the core, which may play a sizable role at high temperature, being in most cases below the reference temperature $\left(500^{\circ} \mathrm{C}\right)$ for the entire duration of the fire. (At room temperature, the share of the twisting moment taken by the core in the elastic domain may range from $5-10 \%$ to $10-15 \%$, depending on section size and reinforcement.)

For both shear and torsion, the contribution of the various shear-transfer mechanisms and some examples are presented and discussed.

\section{SHEAR AND TORSION IN FIRE-EXPOSED CONCRETE MEMBERS}

The behavior of $\mathrm{R} / \mathrm{C}$ members exposed to high temperature or fire is similar to the behavior in ordinary environmental conditions, as concrete remains a rather brittle material even at high temperature. (Its tensile strength is more affected by high temperature than its compressive strength, but less than its elastic modulus). Concrete, therefore, fails in tension, and cracks are controlled by principal stresses.

As for reinforcement, its elastic-plastic-hardening behavior tends to become elastic-plastic and even mostly plastic at very high temperatures (above $500^{\circ} \mathrm{C}$ ).

Cracks tend to be initially at $45^{\circ}$ to the axis if shear or torsion prevails over the other internal forces. In the case of shear, however, the cracks tend to become vertical close to the intrados in tension and increasingly horizontal the closer they are to the neutral axis (i.e. close to the top fibers in compression).

In shear, the cracks at roughly $45^{\circ}$ typical of transversely-reinforced $\mathrm{R} / \mathrm{C}$ beams suggest the formation of a 2D truss system (Ritter-Mörsch truss system, Figure 2a left), while the rather flat cracks typical of transversely-unreinforced $\mathrm{R} / \mathrm{C}$ beams suggest arch-and-tie behavior (Figure 2a right).

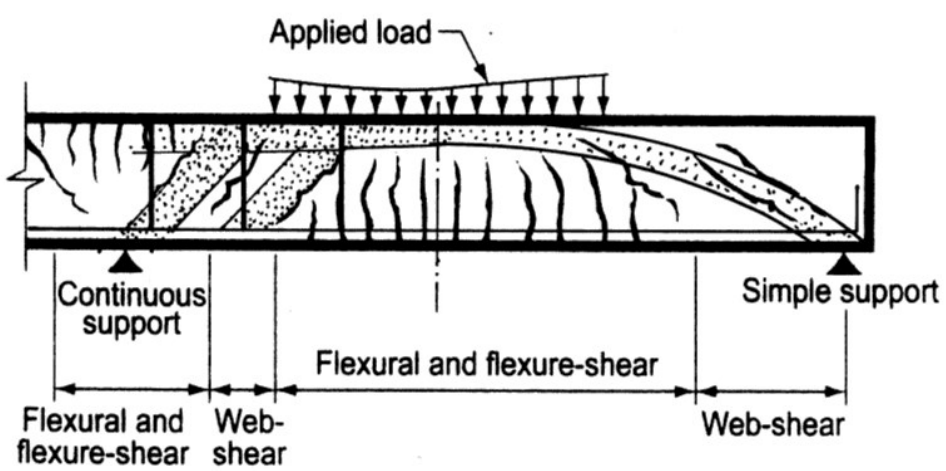

(a)

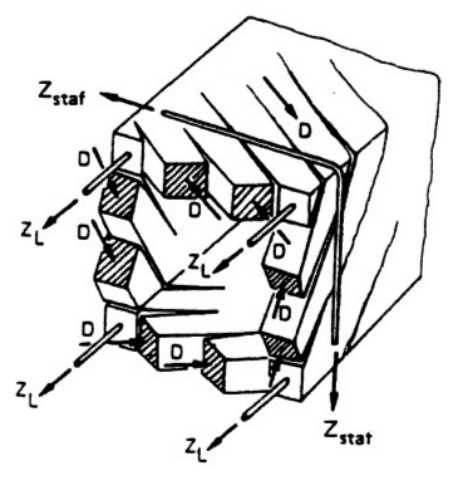

(b)

Figure 2. R/C beam (a) in shear, with the formation of a truss system (left) or of an archand-tie system (right) in transversely-reinforced/unreinforced sections, respectively (adapted

from ACI 318M-08, 2008); and (b) in torsion with the formation of a 3D truss system

(Fuchssteiner, see Leonhardt, 1973). 
In torsion, only transversely-reinforced members make sense; the cracks tend to develop according to spirals inclined by $45^{\circ}$ (or less, should a compressive force be applied), with the formation of a 3D truss system (Figure $2 \mathrm{~b}$ ).

\section{DESIGN MODELS IN SHEAR AND TORSION}

The same models introduced for shear and torsion in $\mathrm{R} / \mathrm{C}$ and $\mathrm{P} / \mathrm{C}$ design at room temperature may be used in fire, provided that the mechanical properties of the materials and/or the geometry of the section be updated according to the thermal field.

The above-mentioned models, however, have not been validated in fire conditions (EC2, 2005: «shear - and torsion - failures due to fire are very uncommon .... the calculation methods ... are not fully verified», Annex D, EN 1992-1-2:2004), as the number of experimental and numerical studies on shear and torsion in fire is fairly limited (as recently observed by Youssef et al., 2015) and often focused on special structures. (A few examples on shear: Felicetti and Gambarova, 1999 for deep beams; Fellinger et al., 2005, and Msaad and Chefdebien, 2007, for hollow-core slabs; Hertz, 1985, Taerwe et al., 2006, Kodur and Hatinger, 2011, and Bamonte et al., 2011 for P/C beams; Smith et al., 2011, and Youssef et al., 2015 for R/C beams; Faria et al., 2010, and Kotsovos and Kotsovos, 2013 for R/C frames and linear members; Lim et al., 2004, and Ali and Nadjai, 2011 for slabs. On the contrary, many are the studies on bending and axial loading (Kordina, 1979; Ellingwood and Lin, 1991; Desai, 1998); Hsu and Lin, 2008; ElFitiany and Youssef, 2009, just to cite a few).

In shear, the simple approach based on a reduced section or effective section can be used; its assumptions are:

- no damage at all in both concrete and reinforcement enveloped by a reference isotherm (generally the $500^{\circ} \mathrm{C}$ isotherm in ordinary concrete);

- full damage (no strength) in the concrete outside the reference isotherm;

- in each reinforcing bar outside the reference isotherm, the strength should be that which corresponds to the actual temperature provided by thermal analysis.

This approach was initially introduced for bending under standard-fire conditions, but was later shown to be reliable - and conservative - under eccentric axial forces. Its assumptions, however, are consistent with shear behavior.

A conceptually similar, but more refined approach is based on the subdivision of the section into zones (generally parallel to the isothermal lines and - consequently mostly aligned with the largest surfaces subjected to heat flux). Each zone has a uniform temperature (equal to the mean temperature dictated by the thermal analysis for that zone, neglecting reinforcement); once an effective thickness (never larger than the actual thickness) is determined, the ensuing reduced section is assigned a uniform temperature equal to the temperature evaluated by means of the thermal analysis in the centroid of the same section; at this stage, the reduced section is introduced into the static analysis. Contrary to the reduced/effective-section method, the zone method takes account of concrete decay due to high temperature. (The properties of the concrete inside the reduced section have to be updated on the basis of the actual temperature of the section; as for the reinforcement, its properties have to be introduced in accordance with the actual temperature of each bar). 
In checks for fire resistance in shear, both approaches can be used, provided that the temperature of the stirrups be evaluated in the most highly stressed point (reference point $P$, Figure 2a), according to the thermal field. The key aspect of the problem is how to identify the reference point, since both temperature and stress in the stirrups are not uniform. Indeed, the temperature tends to decrease towards the top of the section so that the mean temperature of the stirrups is slightly lower than that of the surrounding concrete (Tattoni, 2005; Campanale, 2005). EC2 (2005) recommends using the point located on the chord a-a (Figure 3a) between the effective tension area and the rest of the section.

In torsion, the analogy with the hollow prism can still be used in fire; the entire reinforcement (stirrups - or ties - and longitudinal bars) and the inclined concrete struts are involved in resisting the applied torque (Fig. 3b). Point P may be chosen as the hottest point among those lying in the mid sections of the sides (chord a-a).

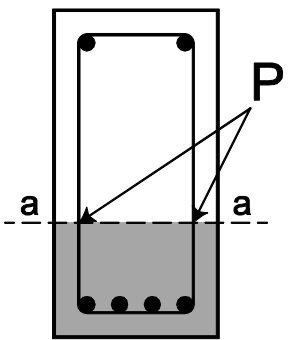

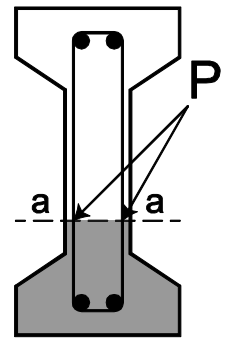

effective tension area

(a) shear

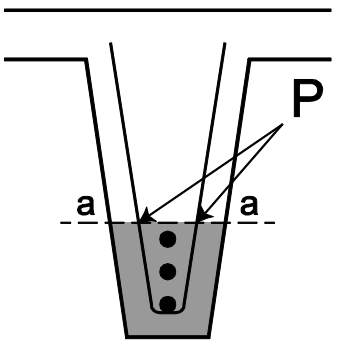

(b) torsion

Figure 3. Identification of the point $\mathrm{P}$ for the evaluation of the reference temperature of the stirrups $(\mathrm{EC} 2,2005)$.

To evaluate the bearing capacity in shear and in torsion, the equations provided in EC2 (2005) are presented below $\left(\gamma_{c}=\gamma_{s}=1\right.$; reference isotherm $500^{\circ}$ when requested; not all the limits of validity of the equations are reported):

Bearing capacity in shear of transversely-unreinforced rectangular $\mathrm{R} / \mathrm{C}$ beams (the top side is in adiabatic conditions, Figure 4a)

According to EC 2, the resisting shear force has the following expression:

$$
\mathrm{V}_{\mathrm{Rc}, \text { fire }}=\left[\mathrm{C}_{\mathrm{R}, \mathrm{c}} \mathrm{k}\left(100 \rho_{\mathrm{l}}^{*} \mathrm{f}_{\mathrm{ck}}{ }^{20}\right)^{1 / 3}\right] \mathrm{b}_{\mathrm{w} \text {,fire }} \mathrm{d}_{\text {fire }}
$$

where $C_{R, c}=0.18 ; \mathrm{k}=1+(200 / \mathrm{d})^{1 / 2} \leq 2 ; b_{\mathrm{w}, \text { fire }}=$ reduced width of the effective section; $\rho_{1}{ }^{*}=\rho_{1}\left(f_{c t k}{ }^{T} / f_{c t k}{ }^{20}\right)$ with $\rho_{1}=$ geometric steel ratio $=A_{s} /\left(b_{w} d\right)$; note that: $(a)$ $\mathrm{d}_{\text {fire }}=\mathrm{d}$ is constant if the moment is positive and the tension reinforcement is arranged on one layer (hence, its centroid does not move during the fire, Figure 4a); and (b) $d_{\text {fire }}$ is variable during the fire if the moment is negative (Figure $4 b$ ).

Bearing capacity in shear in transversely-reinforced rectangular $\mathrm{R} / \mathrm{C}$ beams (crack angle $\theta=45^{\circ}$; the top side is in adiabatic conditions)

According to EC 2, the resisting shear force has the following expression:

$$
V_{R, \text { fire }}=V_{R s, \text { fire }}=\left(A_{s w} / s\right) Z_{\text {fire }} f_{y w k}{ }^{T} \leq V_{R m a x, f i r e}=V_{R c, f i r e}=1 / 2 \alpha_{c w} b_{w, \text { fire }} Z_{\text {fire }} v f_{c k}^{20}
$$



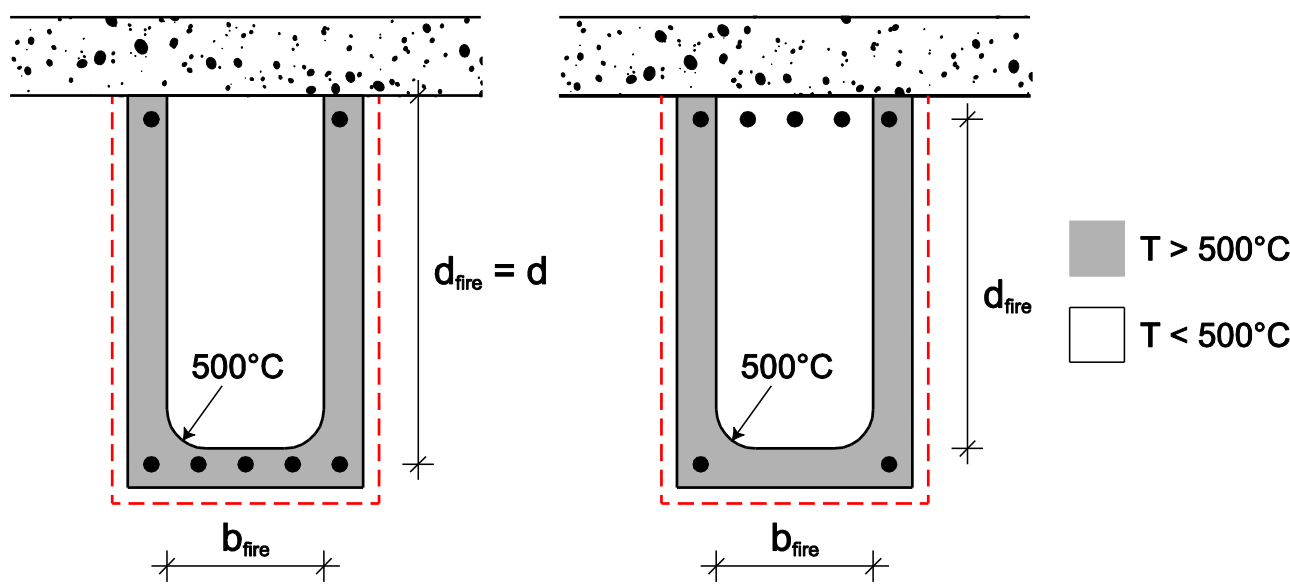

Figure 4. Rectangular section exposed to the fire on three sides: (a) positive moment; and (b) negative moment.

where $v=0.6\left(1-\mathrm{f}_{\mathrm{ck}}^{20} / 250\right) ; \alpha_{\mathrm{cw}}=1$ (no axial force in compression); $\mathrm{A}_{\mathrm{sw}}=$ section of each stirrup times the number of legs (only external legs); $\mathrm{s}=$ stirrup spacing;

$\mathrm{z}_{\text {fire }}=$ internal lever arm $\left(=0.9 \mathrm{~d}_{\text {fire }}\right.$, Fig. 4$)$; note that all the external legs of the stirrups are assumed to be at the same temperature.

Note that Eqs. 2a,b are the same equations introduced in the design at ambient temperature, provided that the characteristic values $\mathrm{f}_{\mathrm{ywk}}{ }^{\mathrm{T}}$ and $\mathrm{f}_{\mathrm{ck}}{ }^{20}$ are replaced with the design values $f_{y w d}$ and $f_{c d}$, and $b_{w, f i r e}$ is replaced with the value $b_{w}$ dictated by geometry. According to Eqs. 2a,b, the bearing capacity yielded by the stirrups (Eq. 2a) should never exceed that provided by concrete struts (Eq. 2b), to guarantee ductile failures (preceded - or accompanied - by stirrup yielding). In the design at ambient temperature, equating Eqs. 2a and $2 \mathrm{~b}\left(\right.$ for $\theta=45^{\circ}$ ) provides the largest possible steel area $A_{s w, m a x}$ to guarantee sectional ductility in ordinary conditions. In fire, $\mathrm{V}_{\mathrm{Rs} \text {,fire }}$ is always smaller than $\mathrm{V}_{\mathrm{Rc} \text {,fire }}$ because of the greater heat sensitivity of the stirrups compared with the much colder - and less heat-sensitive - concrete struts. Consequently, the shear capacity in fire $V_{R \text {,fire }}$ is the same as the shear capacity provided by the stirrups after yielding $\mathrm{V}_{\mathrm{Rs}}$,fire, as indicated in Eq. 2a. (The situation may be different in thin-walled members, where concrete struts may become the weakest link of the resisting chain).

Bearing capacity in torsion in transversely-reinforced solid R/C beams $\left(\theta=45^{\circ}\right)$

According to EC 2, the resisting twisting moment has the following expression:

where:

$$
T_{R, f i r e}=\operatorname{Min}\left(T_{R l, f i r e}, T_{R w, f i r e}, T_{R c, f i r e}\right)
$$

$\mathrm{T}_{\mathrm{Rl} \text {,fire }}=$ resisting twisting moment associated with the longitudinal reinforcement $=$ $2 A_{k}\left(A_{s l} / u_{k}\right) f_{y l k}{ }^{\top}$

$\mathrm{T}_{\mathrm{Rw}, \text { fire }}=$ resisting twisting moment associated with the transverse reinforcement $=2$ $\mathrm{A}_{\mathrm{k}}\left(\mathrm{A}_{\mathrm{sw}} / \mathrm{s}\right) \mathrm{f}_{\mathrm{ywk}}^{\mathrm{T}^{*}}$

$\mathrm{T}_{\mathrm{Rc}, \text { fire }}=$ resisting twisting moment associated with the concrete struts $=v_{\text {fire }} \alpha_{c w} A_{k}$ $t_{\text {eff }} f_{\text {ck }}$

with: $A_{k}=$ area enveloped by the mean line of the section of the hollow prism; $A_{\mathrm{sw}}=$ section of each stirrup times the number of the legs (inside each sub-region of the 
hollow prism); $\mathrm{u}_{\mathrm{k}}=$ length of the mean line of the section of the hollow prism; $\mathrm{t}_{\mathrm{eff}}=$ effective thickness of the hollow prism; $\mathrm{T} / \mathrm{T}^{*} / \mathrm{T}^{* *}=$ mean temperature of the longitudinal reinforcement/reference temperature of the stirrups/mean temperature in the concrete of the hollow prism; $\mathrm{f}_{\mathrm{ck}} / \mathrm{f}_{\mathrm{ylk}} / \mathrm{f}_{\mathrm{ywk}}=$ characteristic strengths of concrete/longitudinal reinforcement/transverse reinforcement; all the longitudinal bars are assumed to be at the same temperature, as are all the stirrups.

\section{REINFORCED AND UNREINFORCED BEAMS IN SHEAR}

\section{Solid sections}

A rectangular section exposed to the standard fire along three sides was analyzed without/with transverse reinforcement using Eq. 1 and Eq. 2a, respectively. The size of the section was: $\mathrm{b} \times \mathrm{h}=200 \times 400 \mathrm{~mm}$; the longitudinal reinforcement consists of $4 \varnothing 16-\mathrm{mm}$ bottom bars and $2 \varnothing 14-\mathrm{mm}$ top bars (geometric steel ratio of the tension bars $\rho_{1}=1.21 \%$ ); the 2-leg stirrups consist of $\varnothing 10-\mathrm{mm}$ bars spaced by $\mathrm{s}=150 \mathrm{~mm}$ (stirrups ratio $\rho_{\mathrm{w}}=0.52 \%$ ); the covers of the stirrups and of the bars are 21 and 34 $\mathrm{mm}$, respectively.

As expected, in the transversely-unreinforced section the strength $V_{R}{ }^{\prime}=V_{R c \text {,fire }}$ (Eq. 1) is controlled by concrete decay, while in the transversely-reinforced section the strength $V_{R} "=V_{R s, f i r e}$ (Eq. 2a) is controlled by the stirrups and by steel decay. In the case of long-duration fires, the strengths $V_{R}$ ' and $V_{R}$ " tend to converge, because of the heat sensitivity of the reinforcement.

For instance, at the beginning of the fire $(t=0)$ the capacity of the transverselyreinforced section is roughly twice that of the transversely-unreinforced section, while after 3 hours the former capacity is only $50 \%$ higher than the latter. The best stirrups would be, therefore, those with 3 or more legs, as the internal legs are embedded in the well-protected and relatively cold core of the section.

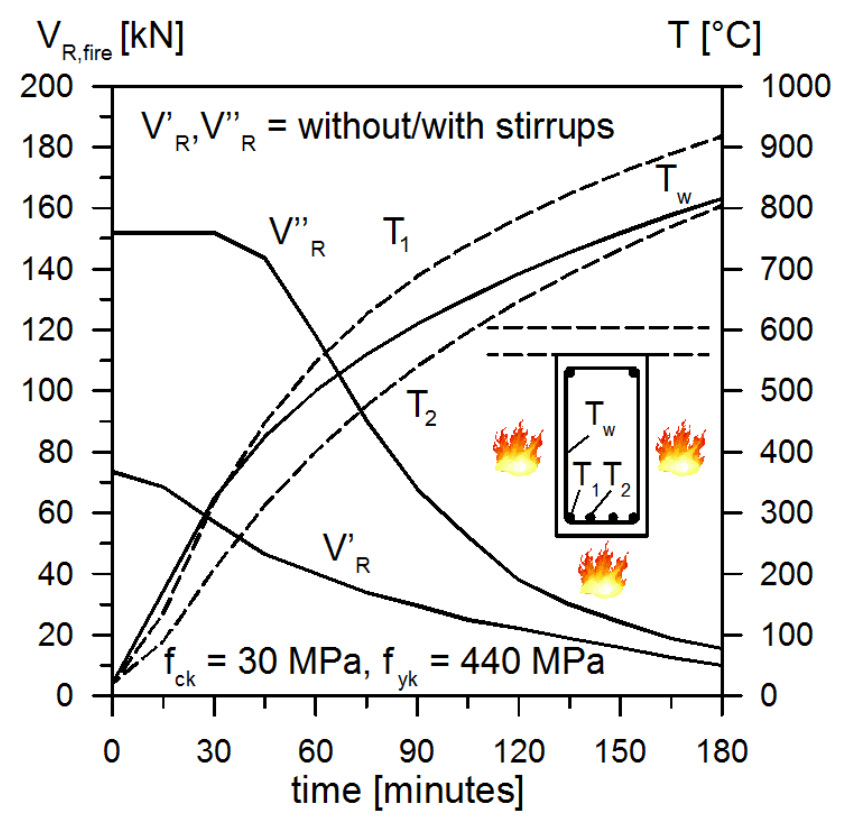

Figure 5. Shear capacity and temperature versus fire duration for an $\mathrm{R} / \mathrm{C}$ section, without and with transverse reinforcement $\left(V^{\prime}{ }_{R}=V_{R c \text { fire, }}\right.$, Eq.1, and $V^{\prime}{ }_{R}=V_{R s, f i r e}$, Eq.2a); 


\section{Open thin-walled sections}

An indirectly-supported inverted-V pre-tensioned beam was studied to evaluate its fire resistance under standard-fire conditions (Fig. 6a; thermal properties from EC2, 2005, from Bamonte et al., 2010). The main geometric characteristics of the beam were: support-to-support span $=12 \mathrm{~m}$, total width and depth $=2.4$ and $1.6 \mathrm{~m}$, respectively; thickness of the wings and angle to the horizontal axis $=90 \mathrm{~mm}$ and $51^{\circ}$. Beside the 7-wire 0.5 in-strands $\left(26\right.$ in all, $\left.\mathrm{f}_{\text {ptk }}=1668 \mathrm{MPa}\right)$, the webs were reinforced with stirrups and bars forming two nets of bars. (In both the longitudinal and transverse directions $\varnothing 8$-mm bars spaced by $70 \mathrm{~mm}$; $\mathrm{f}_{\mathrm{yk}}=500 \mathrm{MPa}$.)

Because of the small thickness of the wings, their effective section goes rapidly to zero (Figure 6a), and the zone method must be applied (Figure 6b).

The normalized strength and the temperature of each of the $4+4$ layers are plotted in Figure 6c.

The reinforcement and the concrete were modelled by means of a truss or strutand-tie system (Figure 7a). The decrease in strength of the main members (Strut 2, and Ties 1 and 4) is plotted in Figure 7b. Fire resistance is close to 50 minutes in the Dregion (Figure $7 \mathrm{~b}$ ) and to 60 minutes in the B-region.

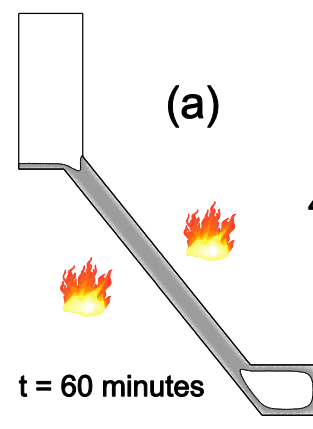

(b)

Figure 6. Isotherm $500^{\circ} \mathrm{C}$ for $\mathrm{t}=60$ minutes of standard fire (a); subdivision into $4+4$ zones of the wings (b); and plots of the strength decay and of the temperature in the $4+4$ zones or layers (c), from Bamonte et al. (2010).
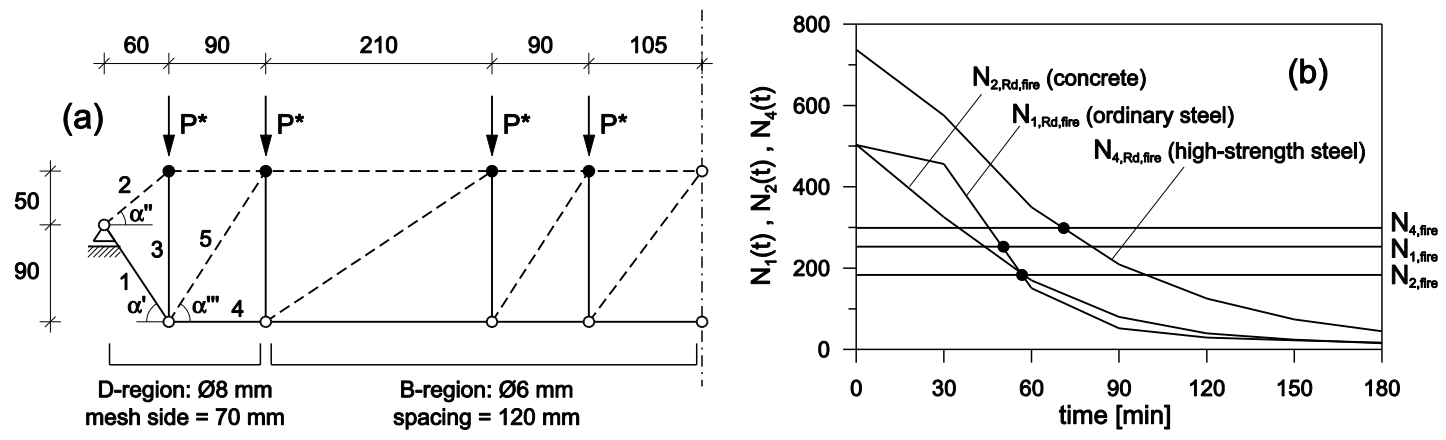

Figure 7. Strut-and-tie model adopted for each wing (a); and strength decay in the main members of the D-region; $\mathrm{P}^{*}$ (own weight included) $=82 \mathrm{kN}$, from Bamonte et al. (2010).

Even if fire resistance is controlled by ordinary steel, which fails first (time to failure close to $50 \mathrm{~min}$, Fig. 7b), the struts of the highly heat-sensitive thin webs follow soon after (time to failure slighly over $55 \mathrm{~min}$ ), as a demonstration that in thin-walled sections concrete may play a critical role, contrary to what happens in solid sections. 


\section{REINFORCED MEMBERS IN TORSION}

\section{Rectangular section}

A transversely-reinforced rectangular section exposed to the standard fire along four sides (Figure 8) was analyzed using Eq. 3. The three resisting moments (or capacities in torsion) provided by the stirrups $\left(\mathrm{T}_{\mathrm{Rw}}\right.$ and $\left.\mathrm{T}_{\mathrm{Rw}}{ }^{*}\right)$, by the longitudinal bars $\left(\mathrm{T}_{\mathrm{Rl}}\right)$ and by the $45^{\circ}$ - concrete struts $\left(\mathrm{T}_{\mathrm{Rc}}\right)$ are plotted in Fig. $8 \mathrm{a}$ as a function of fire duration, together with the average temperatures $T_{w}, T_{1}$ and $T_{c}$.

Note that (a) only with the higher stirrup amount the strength decay is controlled by concrete $\left(\mathrm{T}_{\mathrm{Rc}}\right)$ for $\mathrm{t}<80-85$ minutes, and $(\mathrm{b})$ in the former case the longitudinal and transverse reinforcements are almost balanced $\left(\rho_{1}=1.95 \% ; \rho_{\mathrm{w}}=1.92 \%\right)$.
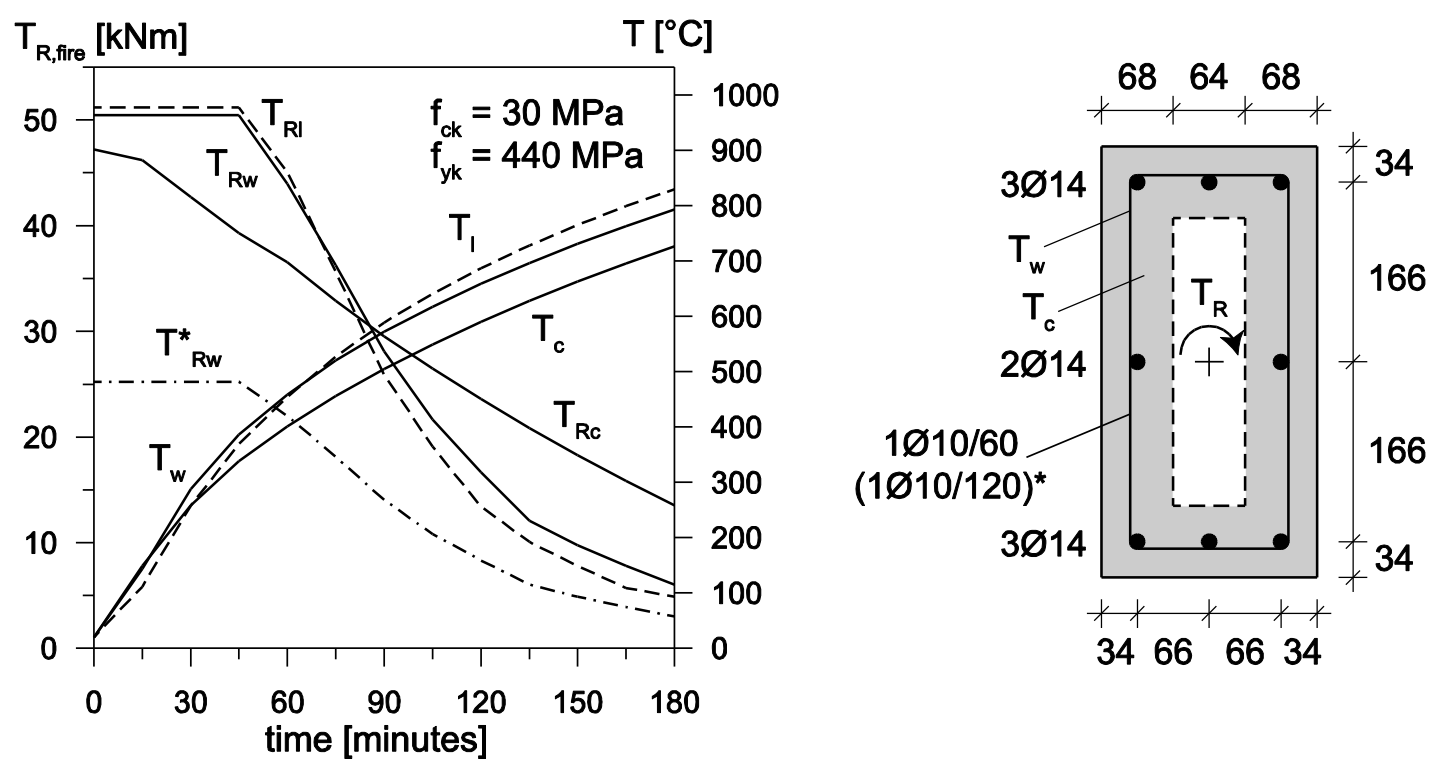

Figure 8. Resisting moments in torsion $\mathrm{T}_{\mathrm{Rw}}, \mathrm{T}_{\mathrm{Rw}}{ }^{*}, \mathrm{~T}_{\mathrm{Rl}}$ and $\mathrm{T}_{\mathrm{Rc}}$, and temperatures $\mathrm{T}_{\mathrm{w}}, \mathrm{T}_{\mathrm{c}}$ and $\mathrm{T}_{1}$ vs. fire duration (standard fire) for a rectangular $\mathrm{R} / \mathrm{C}$ section: $1, \mathrm{w}\left(\mathrm{w}^{*}\right)=$ longitudinal, transverse reinforcement; $\mathrm{c}=$ concrete struts; stirrup $/$ bar cover $=22 / 34 \mathrm{~mm}$.

\section{Role of section core}

The share of the applied twisting moment resisted by the core of a solid R/C section is generally neglected, because it is much smaller than the share resisted by the section of the equivalent hollow prism. In case of fire, however, the core remains cold even during prolonged fires (depending on section size). The role of core may, therefore, become sizable in fire, as it increases with the duration of the fire.

As a demonstration, three square sections of different size are analyzed in Fig. 8, with the focus on their linearly-elastic behavior (only the concrete is considered; the reinforcement - whose steel ratio is close to $2 \%$ - is required only to quantify the thickness $t^{*}$ of the equivalent hollow prism). The elastic properties of the concrete $\left(E_{c}\right.$ and $\left.v_{c}\right)$ are a function of the mean temperatures of the hollow prism and of the core under standard-fire conditions (EC2, 2005; Bahr et al., 2013).

The geometry of the sections is indicated in Fig. 9, together with the reinforcement (net cover of the bars $\mathrm{c}=1.5 \varnothing=24 / 27 / 33 \mathrm{~mm}$; thickness of the hollow core $\mathrm{t}^{*}=2 \mathrm{c}+\varnothing=64 / 72 / 88 \mathrm{~mm}$ ). Concrete properties at $20^{\circ} \mathrm{C}$ are: $\mathrm{f}_{\mathrm{c}}=40$ 
$\mathrm{MPa} ; \mathrm{f}_{\mathrm{t}}=4.0 \mathrm{MPa} ; \mathrm{E}_{\mathrm{c}}=33 \mathrm{GPa} ; v_{\mathrm{c}}=0.19$; according to the theory of elasticity, first-cracking moments are: $6.7 / 22.5 / 53.3 \mathrm{kNm}$, respectively $\left(\tau_{\max }=\mathrm{f}_{\mathrm{t}}\right)$.

As the hollow prism and the core work in parallel, the shares of the applied moment resisted by the whole section $T_{R}$, by the core $T_{R c o}$ and by the equivalent hollow prism $\mathrm{T}_{\mathrm{Rep}}$ are proportional to the torsional stiffnesses:

$$
\mathrm{T}_{\mathrm{R}} \approx \mathrm{G}_{\mathrm{c}} \mathrm{J}_{\mathrm{P}} ; \mathrm{T}_{\mathrm{Rco}} \approx \mathrm{G}_{\mathrm{c}, \mathrm{co}} \mathrm{J}_{\mathrm{Pco}} ; \mathrm{T}_{\mathrm{Rep}} \approx \mathrm{G}_{\mathrm{c}, \mathrm{ep}} \mathrm{J}_{\mathrm{Pep}}
$$

where $J_{P}, J_{P c o}$ and $J_{P e p}$ are the polar moments (constant), and $G_{c}, G_{c, c o}$ and $G_{c, e p}$ are the shear moduli of the concrete (whole section, core and hollow prism, respectively), based on the mean temperature of the whole section or of each part, for any given fire duration.

In Fig. 9a the continuous and dash-dotted curves refer to the normalized moments resisted by the hollow prism and by the core, respectively, for the three sections under investigation. (The normalizing factor is the moment resisted by the whole section at any given fire duration.) In Fig. $9 \mathrm{~b}$ the three continuous curves refer to the normalized moments resisted by the whole sections. (The normalizing factor is the moment resisted by the whole section at the beginning of the fire.)

Note that fire duration yields a marked decrease in both the moment resisted by the whole section (Fig. 9b) and in that resisted by the hollow prism (continuous curves in Fig. 9a), while the moment resisted by the core (dash-dotted curves in Fig. 9a) markedly increases in relative terms.

As an example, let us consider the $300 \times 300 \mathrm{~mm}$ section: after a 3-hours fire the torsional resistance of the whole section is close to $22 \%$ of the original resistance, but $33 \%$ of the residual resistance is provided by the core. After a 4-hours fire, the residual resistance of the section is less than $10 \%$ of the original resistance, but the residual resistance is entirely provided by the core. Last but not least, cracking further weakens the hollow prism compared with the core.
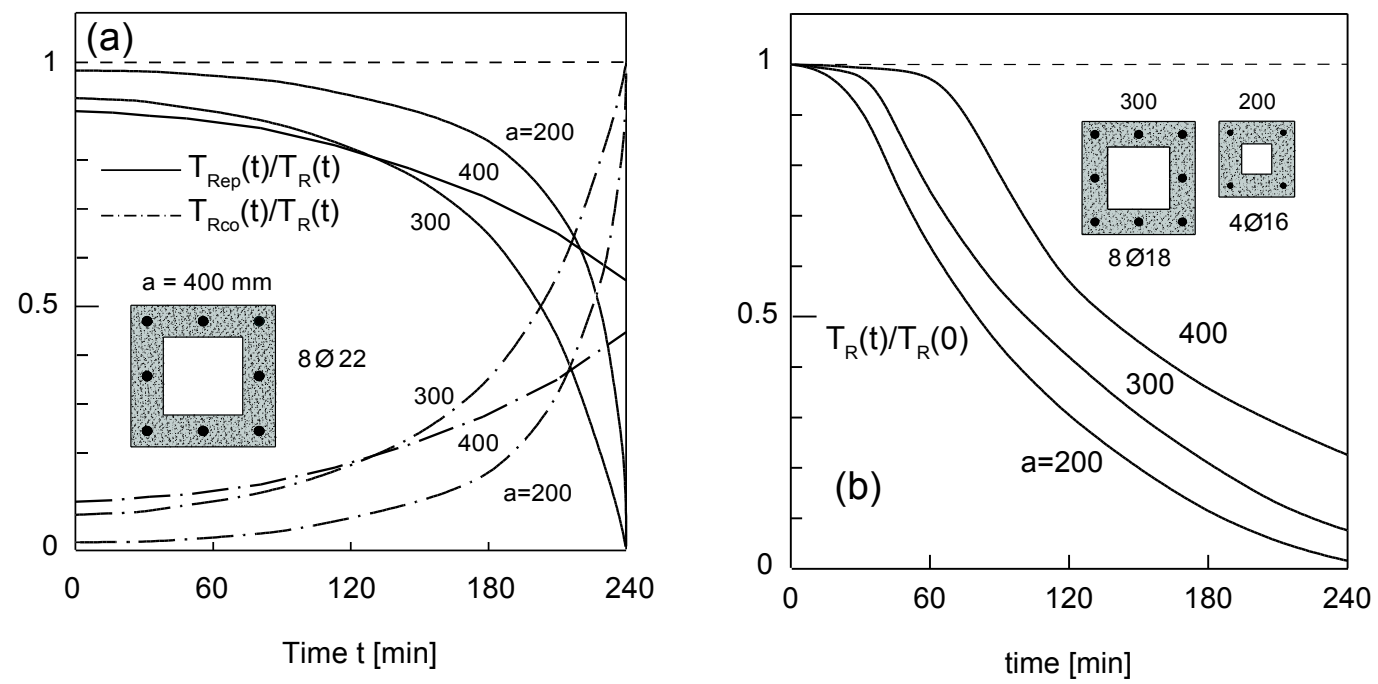

Figure 9. Normalized capacity in torsion of square elastic sections subjected to the standard fire: (a) shares of the applied moment resisted by the hollow prism $\left(\mathrm{T}_{\mathrm{Rep}}\right)$ and by the core $\left(\mathrm{T}_{\mathrm{Rco}}\right)$; and (b) capacity of the sections $\left(\mathrm{T}_{\mathrm{R}}=\mathrm{T}_{\mathrm{Rep}}+\mathrm{T}_{\mathrm{Rco}}\right)$ as a function of fire duration. 


\section{SHEAR-TRANSFER MECHANISMS}

To understand the mechanical decay in fire of an $\mathrm{R} / \mathrm{C}$ member subjected to shear stresses properly (be they due to a shear force or to a twisting moment), the local mechanisms contributing to shear transfer should be analyzed in the context of high temperature and fire, to justify the rather indirect and simplified way these mechanisms are dealt with in the design equations.

Let us consider the case of Fig. 10, where the I-section introduced by Di Prisco and Gambarova (1995) is shown, together with two different kinematics for the inclined cracks. (The bottom chord is assumed to be cracked in $\mathrm{R} / \mathrm{C}$ and uncracked in $\mathrm{P} / \mathrm{C}$, while the thin web is assumed to be cracked in both cases).

The various shear-resistant mechanisms considered in this section are: (a) aggregate interlock INT, activated by the roughness of the inclined cracks; (b) dowel action DWL activated by the local bending of the tension reinforcement; (c) shear in the compressed chord BND, required by the equilibrium of the diagonal concrete teeth subjected to bending (comb-like effect); and (d) stirrups STR. The extension to high temperature of these mechanisms was performed by Campi and Spirio (2012), who also took into account tension-stiffening in the stirrups.

(a) $P / C$ stirrups $R / C$ (b)
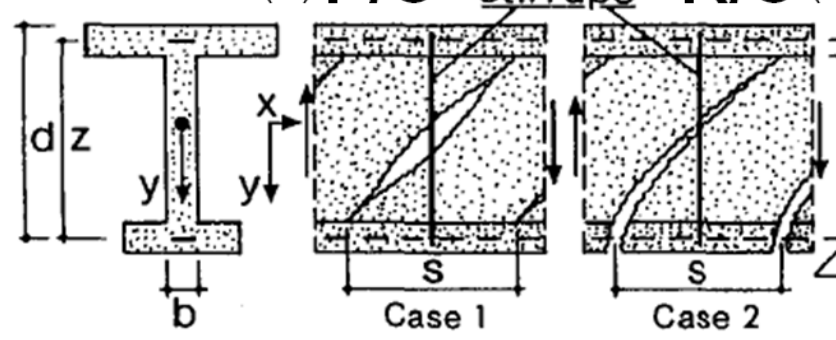

(c)

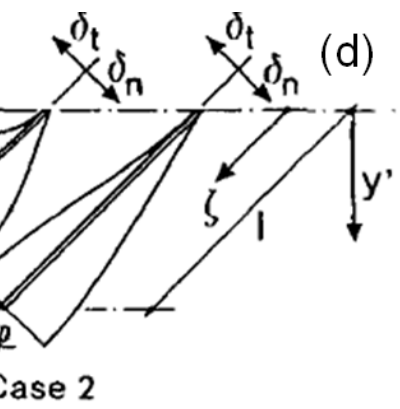

Figure 10. Modelling of web cracking in $\mathrm{P} / \mathrm{C}$ (a) and in $\mathrm{R} / \mathrm{C}$ (b), with the laws adopted to describe interface kinematics $(\mathrm{c}, \mathrm{d})$, where $\delta_{\mathrm{t}}=$ slip and $\delta_{\mathrm{n}}=$ crack opening (Di Prisco and Gambarova, 1995, with permission from ASCE).

Ultimately, this produced a rather complex system of equations based on sectional and local equilibriums, compatibility and the constitutive behavior of the materials. The normalized contributions to shear capacity were calculated in the case of a typical I beam (Figs. 11a,b), as a function of fire duration (Standard Fire ISO 834; thermal properties from EC2).

Note that, in contrast to $\mathrm{R} / \mathrm{C}$ sections (Fig. 11a), dowel action is not active in $\mathrm{P} / \mathrm{C}$ sections (Fig. 11b).

The geometry and the mechanical properties of the beams were: section depth $\mathrm{h}=$ $1100 \mathrm{~mm}$; chords: $600 \times 200 \mathrm{~mm}$; web thickness $=120 \mathrm{~mm}$; in the $\mathrm{R} / \mathrm{C}$ beam (Fig. 11a): crack inclination $\alpha_{\mathrm{cr}}=40^{\circ}, \mathrm{f}_{\mathrm{ck}}=30 \mathrm{MPa}, \rho_{1}=2 \%, \varnothing_{1}=18 \mathrm{~mm}$ and stirrup spacing $\mathrm{s}=100 \mathrm{~mm}$; in the $\mathrm{P} / \mathrm{C}$ beam (Fig. $11 \mathrm{~b}$ ): $\alpha_{\mathrm{cr}}=30^{\circ}, \mathrm{f}_{\mathrm{ck}}=45 \mathrm{MPa}$ and $\mathrm{s}=150$ $\mathrm{mm}$; in both cases: stirrup diameter $\varnothing_{\mathrm{st}}=8 \mathrm{~mm}$ (2 legs), $\mathrm{f}_{\mathrm{yk}}=440 \mathrm{MPa}$ and max. aggregate size $d_{a}=20 \mathrm{~mm}$.

The two major contributions are yielded by the stirrups $(70-75 \%$ of the shear capacity at room temperature) and by aggregate interlock (20-25\%). The former is not affected by the fire as long as bar temperature remains below $400^{\circ} \mathrm{C}$ (hot-rolled stirrups), and later starts decreasing. The latter starts decreasing earlier, as crack 
opening tends to increase at high temperature more than crack slip, because of increasing structural deformability).

The contributions of dowel action (in $\mathrm{R} / \mathrm{C}$ ) and teeth bending (in $\mathrm{R} / \mathrm{C}$ and $\mathrm{P} / \mathrm{C}$ ) to shear transfer are markedly less significant both at room temperature (the total contribution is comprised between 5 and $10 \%$ ) and at high temperature, but $\mathrm{V}_{\mathrm{DWL}}$ totally vanishes after 30 minutes primarily because of the heat-induced damage in the cover, while $\mathrm{V}_{\mathrm{BND}}$ decreases regularly - and almost linearly - both in $\mathrm{R} / \mathrm{C}$ and $\mathrm{P} / \mathrm{C}$ sections, because concrete teeth are subject to a gradual deterioration, proceeding from the heated surface inwards.
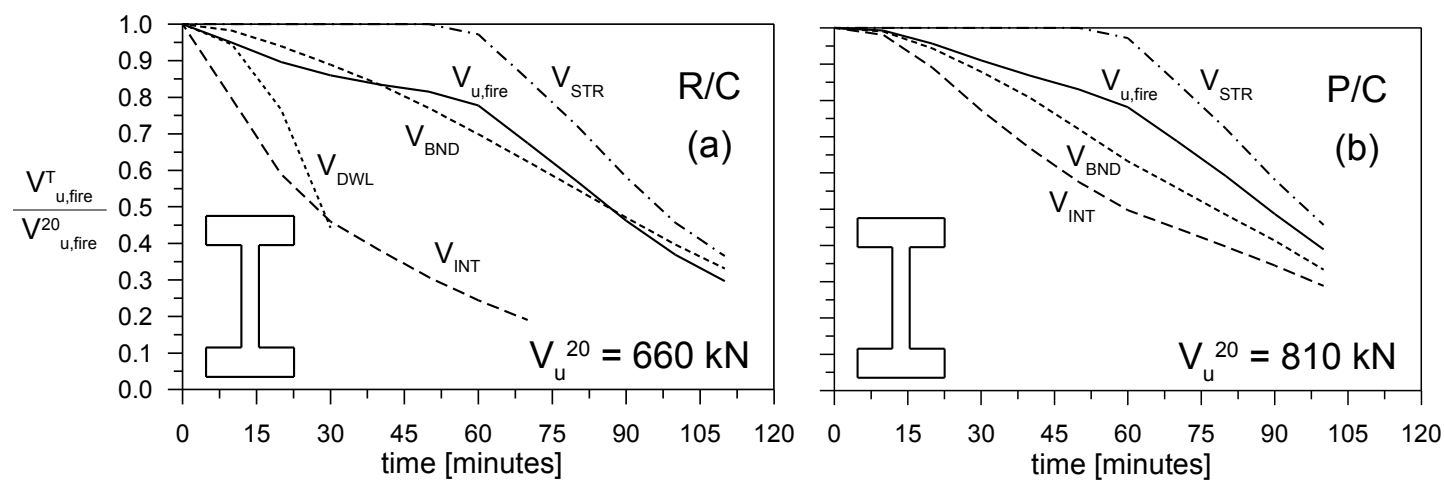

Figure 11. Example of a shear-sensitive double-tee section representing an $\mathrm{R} / \mathrm{C}$ beam (a); and a $\mathrm{P} / \mathrm{C}$ beam (b): plots of the normalized contributions to shear transfer

(Campi and Spirio, 2012).

\section{CONCLUDING REMARKS}

The well-established design models for shear and torsion (beam-end section and 2Dtruss models in shear, and 3D-truss model in torsion) are still consistent with crack evolution at high temperature, and can easily be extended to fire design; experimental evidence is, however, needed.

In shear, the relatively cold core of solid structural members always prevents concrete struts from crushing in fire.

The reduced/effective section method is adequate for solid sections, where (a) the thermal field is highly variable, (b) the reference isotherm $500^{\circ} \mathrm{C}$ envelopes the relatively cold inner part of the section (where the mechanical properties of both concrete and steel are mostly unaffected by the temperature), and (c) the hot outer part of the section is severely damaged by the heat.

The zone method is more general and also covers cases in which the thermal field in the concrete tends to be fairly uniform, as in thin-walled members.

In torsion, medium-size solid sections are given extra strength in a prolonged fire by the cold core, whose contribution may be substantial at high temperature.

In small solid sections, whose torsional capacity is fairly limited even at room temperature, the capacity provided by the core - though small - may be the only residual capacity left during a moderate-to-serious fire.

With reference to the two major shear-transfer mechanisms, the contributions of the stirrups and of aggregate interlock decrease with fire duration, gradually (above $400-500^{\circ}$ ) in the former case and fairly sharply in the latter case. The reasons are: for the stirrups the decreasing strength at yielding of the steel (above $400-500^{\circ} \mathrm{C}$ ) 
and for aggregate interlock the increasing role of crack opening with the temperature, because of the increasing structural deformability.

As for the two minor shear-transfer mechanisms, the contribution of teeth bending (also known as comb-like effect) regularly and almost linearly decreases with fire duration, while dowel action (only in $\mathrm{R} / \mathrm{C}$ members) rapidly declines to zero, because of the heat-induced damage in the concrete cover protecting the longitudinal bars.

On the whole, even in fire stirrups and aggregate interlock remain the main actors. However, the latter contributes far less than it does at room temperature.

\section{ACKNOWLEDGEMENTS}

The authors would like to thank Professor Thomas T.C. Hsu for his suggestions during the workshop on "Shear and Torsion Resistance of R/C Structures" organized on June 17, 2015, at the Politecnico di Milano (Milan, Italy) by Prof. Marco Di Prisco. On that occasion, the second author presented an overview on the fire design of $\mathrm{R} / \mathrm{C}$ in shear and torsion.

\section{REFERENCES}

ACI 318M-08 and Commentary (2008). Building Code Requirements for Structural Concrete, Chapter 11 "Shear and Torsion", and Appendix A "Strut-and-Ties Models": 379-394.

Ali, F., and Nadjai, A. (2011). An Experimental and Numerical Investigation on the Performance of High Strength Concrete Slabs during Fire. ACI SP 279: 201-231.

Burnier, O. (2016). Shear Breaking of Columns Subjected to Localized Fire. Proc. $9^{\text {th }}$ Int. Conf. "Structures in Fire" - SIF 2016. Maria E. Moreyra Garlock and Venkatesh K.R. Kodur eds., DEStech Publications Inc.-Lancaster (Pa, USA), Princeton (NJ, USA) June 8-10, 2016: 885-892.

Bahr, O., Schaumann, P., Bollen, B., and Bracke, J. (2013). Young's modulus and Poisson's ratio of concrete at high temperatures: Experimental investigations. Materials and Design, V.45: 421429.

Bamonte, P., Felicetti, R., Gambarova P.G. and Giuriani E. (2010). Thin-Walled Open-Section P/C Beams in Fire: a Case Study. Proc. Workshop on "Shear and Punching-Shear in RC and FRC Elements” - Fib Bulletin No. 57, Salò (Italy), October 15,16: 173-193.

Bamonte, P., Felicetti, R., Gambarova P.G. (2011): On fire safety of thin-walled P/C beams subjected to cracking and corrosion. ACI SP 279 "Innovations in Fire Design of Concrete Structures", ed. by V.K.R. Kodur: 137-169.

Campanale F. 2005. On the Shear Resistance of R/C Members in Fire Based on Available Experimental and Numerical Results (in Italian). MS Dissertation supervised by Professor Sergio Tattoni, Politecnico di Milano, April 2005: 175 pp.

Campi, G.A., and Spirio, D.A. 2012. "On the Shear Behavior of R/C and P/C Thin-Walled Members Exposed to high Temperature" (in Italian). MS Dissertation supervised by Dr. Patrick Bamonte, Politecnico di Milano, December 2012: 170 pp.

Desai S.B. (1998). Design of Reinforced Concrete Beams under Fire Exposure Conditions. Magazine of Concrete Research, V.50, No.1: 75-83.

Di Prisco, M., and Gambarova, P.G. (1995). Comprehensive Model for Study of Shear in ThinWebbed RC and PC Beams. ASCE - Journal of Structural Engineering, V.121, No.12: 18221831.

El-Fitiany S. and Youssef M.A. (2009). Assessing the Flexural and Axial Behaviour of Reinforced Concrete Members at Elevated Temperatures Using Sectional Analysis. Fire Safety Journal, V.44, No.5: 691-703. 
Eurocode 2 - EC2 (EN 1992-1-2, 2005). Design of Concrete Structures - Part 1-2: General Rules Structural Fire Design. CEN, Bruxelles (Belgium).

Ellingwood, B., and Lin, T.D. (1991). Flexure and Shear Behavior of Concrete Beams during Fires, ASCE - Journal of Structural Engineering, V.117, No.2: 440-458.

Faria, R., Xavier, H.F., and Real, P.V. (2010). Simplified Procedure for Shear Failure Assessment of RC Framed Structures Exposed to Fire. Structures in Fire - Proc. Sixth Int. Conf. "Strucures in Fire" - SiF 2010: 197-205.

Felicetti, R., and Gambarova, P.G. (1999). Residual Capacity of HSC Thermally-Damaged Deep Beams. ASCE - Journal of Structural Engineering, V.125, No.3: 319-327.

Fellinger, J., Stark, J., and Walraven, J. (2005). Shear and Anchorage Behaviour of Fire Exposed Hollow Core Slabs. HERON, V.50, No.4, Special Issue on Fire safety, Joris Fellinger and Kees Both eds.: 95-117.

Hertz, K. (1985). Analyses of Prestressed Concrete Structures Exposed to Fire. Report No.174, Institute of Building Design, Technical University of Denmark, Lyngby (DK): 152 pp.

Hsu J. and Lin C. (2008). Effect of Fire on the Residual Mechanical Properties and Structural Performance of Reinforced Concrete Beams. Journal of Fire Protection Engineering, V.18, No.4: 245-274.

Kodur, V.K.T., and Hatinger, N.R. (2011). A Performance-Based Approach for Evaluating Fire Resistance of Prestressed-Concrete Double T-Beams. Journal of Fire Protection Engineering, V.8: 185-222.

Kordina, K. (1979). Über das Brandverhalten von Bauteilen und Bauwerken (On Fire Behavior of Structural Members and Constructions)", Rhein.-Westfäl. Akademie dere Wissenschaften, Report No. 281.

Kotsovos G.M and Kotsovos M.D. (2013). Effect of Axial Compression on Shear Capacity of Linear RC Members without Transverse Reinforcement. Magazine of Concrete Research, V.65, No.22:1360-1375.

Leonhardt, F. (1973). Spannbeton für die Praxis (Structural Concrete in Customary Practice), Ernst Verlag, Berlin.

Lim L., Buchanan A., Moss P. and Franssen J.M. (2004). Numerical Modelling of Two-Way Reinforced Concrete Slabs in Fire. Engineering Structures, V.26, No.8: 1081-1091.

Msaad Y. and Chefdebien A. (2007). Temperature and Shear Capacity Calculation for Prestressed Hollow Core Slabs under Fire Conditions. Proc. Int. Workshop on Fire Design of Concrete Structures - From Materials Modelling to Structural Performance, Coimbra (Portugal): 351-357.

Reineck K.H. (Ed., 2002). Examples for the Design of Structural Concrete with Strut-and-Tie Models. ACI SP-208, 242 pp.

Reineck K.H. and Novak N.C. (Eds., 2010) . Further Examples for the Design of Structural Concrete with Strut-and-Tie Models. ACI SP-273, $288 \mathrm{pp}$.

Smith, H.K.M., Reid, E.R.E., Beatty, A.A., Stratford, T.J., and Bisby, L.A. (2011). Shear Strength of Concrete at Elevated Temperature. Workshop on "Application of Structural Fire Engineering”, Prague (Czech Republic): 133-138.

Taerwe, L., Poppe, A.-M., Annerel, E., and Vandevelde, P. (2006). Structural Assessment of a Pretensioned Concrete Girder after Fire Exposure. Proc. $2^{\text {nd }}$ Int. Congress of fib-Fédération Internationale du Béton, June 5-8, Naples (Italy): $12 \mathrm{pp}$.

Tattoni, S. 2005 "Fire Resistance of Precast Elements: Research Activity within the Italian National Project ULISSE". Proc. Workshop on "Fire Design of Concrete Structures: What's Now? Whats Next?”, Milan (Italy), 2-4 December 2004: 307-310.

Youssef, M.A., Diab, M.A., and El-Fitiany, S.F. (2015). Shear Capacity of RC Beams at Elevated Temperatures. Magazine of Concrete Research, V.67, No.22: 1190-1203. 